\title{
Lung abscess secondary to lung cancer with a coinfection of Granulicatellaadiacens and other bacteria: a case report
}

\author{
Shuo Yang ${ }^{1}$, Liangliang $\mathrm{Wu}^{1}$, Lili X $\mathrm{u}^{2}$, Xiang Huang ${ }^{1}$, Xiaofeng Sun ${ }^{3^{*}} \mathbb{D}$, Lan Yang ${ }^{1}$ and Ling $\mathrm{Xu}^{1}$
}

\begin{abstract}
Background: Granulicatella adiacens is facultative anaerobic Gram-positive bacteria, which mainly involve bacterial endocarditis and bacteremia, but there are few reports of local suppurative infection. A case of lung abscess with a coinfection of Granulicatella adiacens and other bacteria in a lung cancer patient will be reported in this paper. To our knowledge, this is the first case report describing lung abscess due to G.adiacens.

Case presentation: A 52-year-old Chinese woman was admitted to the hospital, She complained of coughing and expectoration for 1 month, shortness of breath for half a month, and dyspnea for 1 day. After a series of examinations, she was diagnosed with lung abscess, pleural effusion, and bronchogenic carcinoma. Draining pus culture demonstrated Granulicatella adiacens. After more than 5 weeks of antibiotic therapies in total, she gradually recovered to fight against lung cancer.

Conclusion: This is the first reported lung abscess caused by G.adiacens. In immunosuppressed hosts, G.adiacens is a virulent pathogen associated with a spectrum of intrathoracic suppurative. Earlier diagnosis and proper drainage surgery with effective antibiotics treatment are very important, and antimicrobial treatment should be more than 5 weeks. When complex pulmonary infection interferes with the $\mathrm{CT}$ diagnosis, clinical suspicion of lung cancer should be increased if G.adiacens or Eikenella corrodens is detected from a pulmonary infection.
\end{abstract}

Keywords: Granulicatella adiacens, Eikenella corrodens, Lung abscess, Lung cancer, Case report

\section{Background}

A lung abscess is defined as a circumscribed area of pus in the lung, which leads to cavity formation and a radiographic finding of an air-fluid in the cavity $[1,2]$. In the past decades, anaerobic bacteria and Streptococcus have been the main type of bacteria in lung abscesses [3]. Granulicatella adiacens is facultative anaerobic Grampositive bacteria and typically involved in cases of bacterial endocarditis [4-7] and bacteremia $[8,9]$. There are few reports of local suppurative infection, only a few isolated reports of suppurative osteomyelitis, arthritis,

\footnotetext{
* Correspondence: xjwlsxf@163.com

${ }^{3}$ Infection center, the First Affiliated Hospital of Xinjiang Medical University, Urumqi city, China

Full list of author information is available at the end of the article
}

encephalitis, ophthalmia, and pulpitis [10-15]. Here, we report a case of lung abscess with a coinfection of G.adiacens and other bacterias in a lung cancer patient. To our knowledge, this is the first case report describing lung abscess due to G.adiacens.

\section{Case presentation}

On October 8, 2020, a 52-year-old Chinese female was admitted to a local state hospital with cough and expectoration, and a chest $\mathrm{CT}$ scan revealed an oblique fissure effusion in the right lung (Fig. 1a), which was diagnosed as a pulmonary infection and treated empirically with levofloxacin at the local state hospital. After 1 week of treatment with this regimen, the patient developed shortness of breath, and the supervising physician

(c) The Author(s). 2021 Open Access This article is licensed under a Creative Commons Attribution 4.0 International License, which permits use, sharing, adaptation, distribution and reproduction in any medium or format, as long as you give appropriate credit to the original author(s) and the source, provide a link to the Creative Commons licence, and indicate if changes were made. The images or other third party material in this article are included in the article's Creative Commons licence, unless indicated otherwise in a credit line to the material. If material is not included in the article's Creative Commons licence and your intended use is not permitted by statutory regulation or exceeds the permitted use, you will need to obtain permission directly from the copyright holder. To view a copy of this licence, visit http://creativecommons.org/licenses/by/4.0/. The Creative Commons Public Domain Dedication waiver (http://creativecommons.org/publicdomain/zero/1.0/) applies to the data made available in this article, unless otherwise stated in a credit line to the data. 



Fig. 1 CT showed oblique fissure effusion of right lung on Oct. 8 (a) and showed huge thick-walled cavity in the right lung on Oct. 31 (b)

adjusted the treatment regimen to levofloxacin combined with latamoxef sodium considering poor infection control. After another 1 week of anti-infective treatment, the patient felt that her symptoms were relieved and asked to be discharged from the hospital and stopped taking antibiotics on her own. After discharge, the patient's shortness of breath gradually worsened, and she went to the local state hospital again on October 31, and a repeat CT scan showed a large thick-walled cavity in the right lung (Fig. 1b). Outpatient doctors suggested that the patient continue hospitalization. On November 1 st, the patient suffered from sudden pain in the right chest and difficulty breathing during hospitalization, so she was transferred to our hospital in the emergency department. She used to have type 2 diabetes without a history of joint pain, heart valvular disease, lung surgery, and no family history of the tumor.

Once admitted, the patient underwent re-examination by $\mathrm{CT}$ that revealed right hydropneumothorax and extensive compression atelectasis (Fig. 2a), and then was diagnosed with pyothorax. Moreover, laboratory inspection including WNWBC $6.5 \times 109 / \mathrm{L}$, PLT $298 \times 109 / \mathrm{L}$, IL$6955.2 \mathrm{pg} / \mathrm{mL}, \quad$ PCT $0.99 \mathrm{ng} / \mathrm{mL}, \quad$ CRP $>90 \mathrm{mg} / \mathrm{L}$, ALB33.02 $\mathrm{g} / \mathrm{L}$, indicated infection and malnutrition, and empirical treatment of moxifloxacin were given in the emergency. On November 3, she was admitted to the intensive care unit. The ultrasonic examination showed that the localized anechoic area of $13.0 \mathrm{~cm} \times 10.1 \mathrm{~cm} \times$ $6.2 \mathrm{~cm}$ in the right thoracic cavity and she was given moxifloxacin plus thoracic puncture and drainage. The

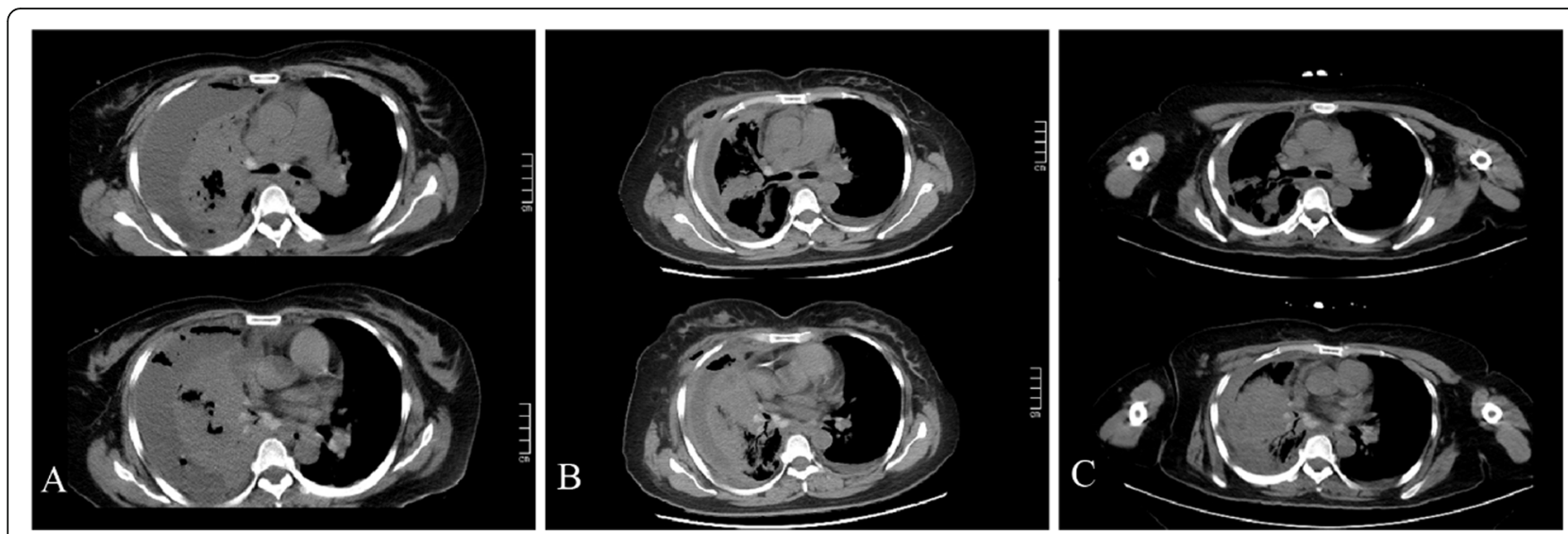

Fig. 2 CT showed hydropneumothorax and extensive compression atelectasis on the right side of the chest on November $1 \mathrm{st}$ (a). After thorough pleural drainage and anti-infective treatment, CT showed right pleural thickening, pleural effusion, multiple cord shadows in the middle and lower lobe, and consolidation of the lower lobe on November 18 (b). On December 7, CT re-examination showed that the multiple cords in the middle and lower lobe of the right lung were obviously absorbed and the consolidation range of the lower lobe was slightly reduced 
drainage was porridge-like, with a fishy smell, and the pus was sent for biochemical examination (Table 1). Dyspnea was improved after drainage of $1300 \mathrm{ml}$ pleural effusion for 2 days.

On November 6, she was transferred to the general ward and continued to be treated with broadspectrum moxifloxacin. At the same time, fibrinolytic drugs were injected into the pleural cavity for $72 \mathrm{~h}$. During the treatment, the symptoms of shortness of breath worsened again, and ultrasound re-examination showed that the localized anechoic area of $12.5 \mathrm{c} \times 6.8$ $\mathrm{cm} \times 6.7 \mathrm{~cm}$ was in the right thoracic cavity. The drainage device was replaced by closed thoracic drainage and intermittent drainage of $1000 \mathrm{ml}$ pleural effusion. The drainage fluid was sent to 2 groups of blood culture on different days (each group included an aerobic bottle and an anaerobic bottle). The equipment is a two-way blood culture bottle, consisting of peptone, beef paste, and other culture media, which is suitable for in vitro culture and detection of various aerobic or anaerobic bacteria in body fluids (blood, pleural fluid, etc.). The culture results showed that there were 3 strains of G.adiacens, 1 strain of Eikenella corrodens, and 1 strain of Staphylococcus aureus. G.adiacens were identified as the main pathogen due to its high detection rate, and the drug sensitivity test showed that it was sensitive to penicillin, erythromycin, vancomycin, cefotaxime, levofloxacin, and linezolid. According to the results of drug sensitivity, we continued to give moxifloxacin treatment (both moxifloxacin and levofloxacin belong to fluoroquinolone antibiotics, with similar antimicrobial spectra and stronger effect of moxifloxacin on cocci and anaerobic bacteria), and additively covered anaerobic bacteria with ornidazole. We also arranged echocardiography and electronic bronchoscopy for the patient. Echocardiography examination showed local calcification of the aortic valve without valvular insufficiency and vegetation, which ruled out endocardial infection. Bronchoscopy examination showed external

Table 1 The biochemistry of pleural effusion suggests empyema, but does not rule out the possibility of tumor

\begin{tabular}{lll}
\hline Pleural effusion biochemistry & & \\
\hline Item & outcome & unit \\
\hline Appearancefaint & yellow & \\
diaphaneity & turbid & \\
Rivalta & + & \\
WBCC & $13,531.0$ & $10^{6} / \mathrm{L}$ \\
Protein & 48.20 & $\mathrm{~g} / \mathrm{L}$ \\
LDH & 3237.00 & $\mathrm{U} / \mathrm{L}$ \\
ADA & 81.50 & $\mathrm{U} / \mathrm{L}$ \\
\hline
\end{tabular}

compressive stenosis of the right middle bronchus (Fig. 3). Besides, minced meat-like tissue of the lower lobe of the right lung was found in the bronchoscopy, and pathological examination revealed adenocarcinoma (Fig. 4). On November 18, CT re-examination showed right pleural thickening, pleural effusion, multiple cord shadows in the middle and lower lobe bottom consolidation (Fig. 2b). After multidisciplinary consultation, it is suggested that surgical intervention should be carried out after the control of pulmonary infection. On November 19, the patient went home with a drainage device and was given oral moxifloxacin and ornidazole as discharge drugs. At the same time, nutritional support lasted throughout the medication period. The patient was revisited On December 7, WBCC and CRP were in the normal range, CT showed right pleural thickening, obvious absorption of multiple cords in the middle and lower lobe of the right lung, and slightly reduced consolidation range of the lower lobe (Fig. 2c). During the telephone followup on December 16, we learned that the patient had successfully removed the closed thoracic drainage tube and was receiving further antineoplastic therapy.

\section{Discussion and conclusions}

In the pre-antibiotic era, lung abscess was caused by one type of bacteria, and nowadays almost of $90 \%$ cases are caused by multiple bacteria [16, 17]. According to Hammond et al. reported that there is an average of 2.3 different bacteria per abscess [18], while G.adiacens, Eikenella corrodens, and Staphylococcus aureus were detected in our case. G.adiacens was identified as the main pathogen after 3 times of detection, but the mixed infection of Eikenella corrodens and Staphylococcus aureus could not be excluded. G.adiacens is a nutritional variant streptococcus (NVS), known as a commensal flora of the human oral, gastrointestinal and genitourinary tracts. It usually grows in chocolate medium or blood medium containing Vit6, L-cysteine, and can also grow around small satellite colonies supported by auxiliary bacteria such as Staphylococcus aureus [19]. The microorganism is sometimes excluded by biochemical tests due to its slow growth and generally needs confirmation by molecular techniques [8]. Recently, MALDI-TOF mass spectrometry has been reported as a rapid and exact tool for the identification of G.adiacens [20], and the use of MALDI-TOF mass spectrometry in clinical laboratories has revolutionized routine bacterial identification, making it faster, more accurate, and cheaper [21]. However, the clinical importance of these bacteria is underestimated by clinicians due to the demanding growth and difficult identification of G. advances [22], while the pulmonary infections caused by G.adiacens may be underestimated. 


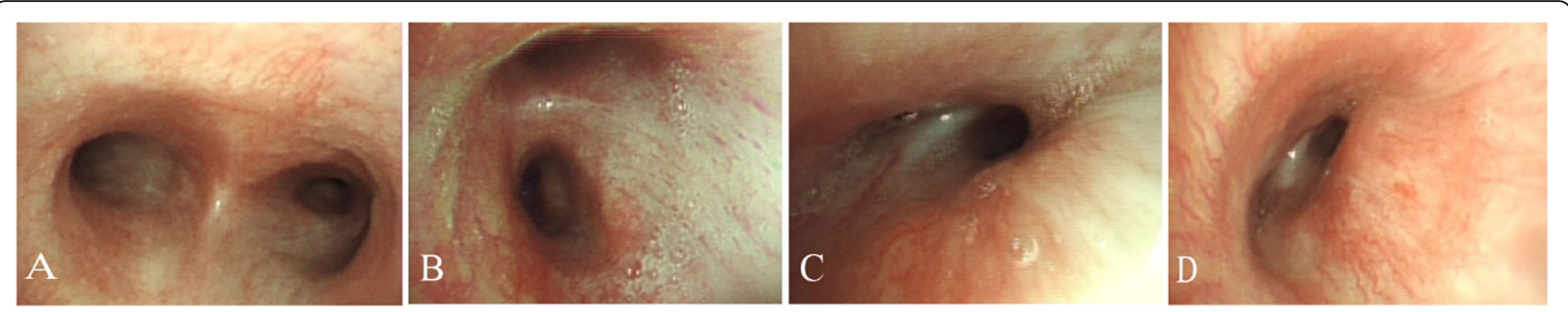

Fig. 3 Tracheal Carina (a), right common bronchus (b), right intermediate bronchus (c and $\mathbf{d}$ ); external compressional stenosis of the right intermediate bronchus is seen in the figure

Our patient had no imaging findings related to lung cancer on multiple CT examinations, and if there is no coincidence bronchoscopy, we would almost ignore the fact that she had lung cancer. This could be catastrophic for the patient, because it would cause her to miss the best time to treat cancer. Tumors, malnutrition, and diabetes may be contributing factors of abscess in this case, and tumors may play the most important role. The tumor microenvironment is characterized by increased inhibitory signals and decreased T cells [23], and studies have shown that $62 \%$ of lung abscess cases have immunosuppression [24]. Leihao $\mathrm{Hu}$ et al. [25] reported an Eikenella corrodens infected lung abscess secondary to lung cancer, and coincidentally 3 strain of G.adiacens and 1 strain of Eikenella corrodens were detected in our case. Similar to G.adiacens, Eikenella corrodens is also a facultative anaerobe colonized in human oral, gastrointestinal and urogenital tract [26]. Immunocompromise due to tumors may allow both species to invade deeper tissues and thrive in carbon dioxide-rich and oxygendeficient lung tissues. Given the specific habits of these bacteria, clinical suspicion of lung cancer should be increased if G.adiacens or Eikenella corrodens are detected in lung infections.

The size of the lung abscess and the location of the right lower lobe are radiological prognostic markers, surgery and catheterization may be considered in patients with a poor prognosis [2], Our patient had a large abscess located mainly in the right lower middle lobe of the lung, which had already invaded the pleural cavity causing massive pleural effusion and extensive compressed pulmonary atelectasis when she came to our hospital, missing the best time for abscess treatment. The American Heart Association (AHA) and the British Society for Antimicrobial Chemotherapy (BSAC) recommend that NVS IE follow the guidelines for enterococcal IE, that is, combined with penicillin or ampicillin plus gentamicin for a duration of 4 to 6 weeks $[27,28]$. NVS is increasingly resistant to penicillin, and only $55 \%$ of G.adiacens were sensitive to penicillin [29]. Few clinical data support the recommended AHA/BSAC regimen for the treatment of NVS IE [30]. Fanny Quénard et al. showed that antimicrobial treatment ( $\geq 8$ weeks) is sufficient for prosthetic joint infection caused by G.adiacens [14]. In our patient, after complete chest drainage and up to 5 weeks of moxifloxacin treatment, there was good resorption of inflammation elsewhere in the right lung on CT scan, although solid lesions in the lower and middle segments were poorly resolved, which demonstrates the need for a course of antibiotics beyond 5 weeks in the lung infections caused by G.adiacens.

This is the first reported lung abscess caused by G.adiacens. In immunosuppressed hosts, G.adiacens is a virulent pathogen associated with a spectrum of

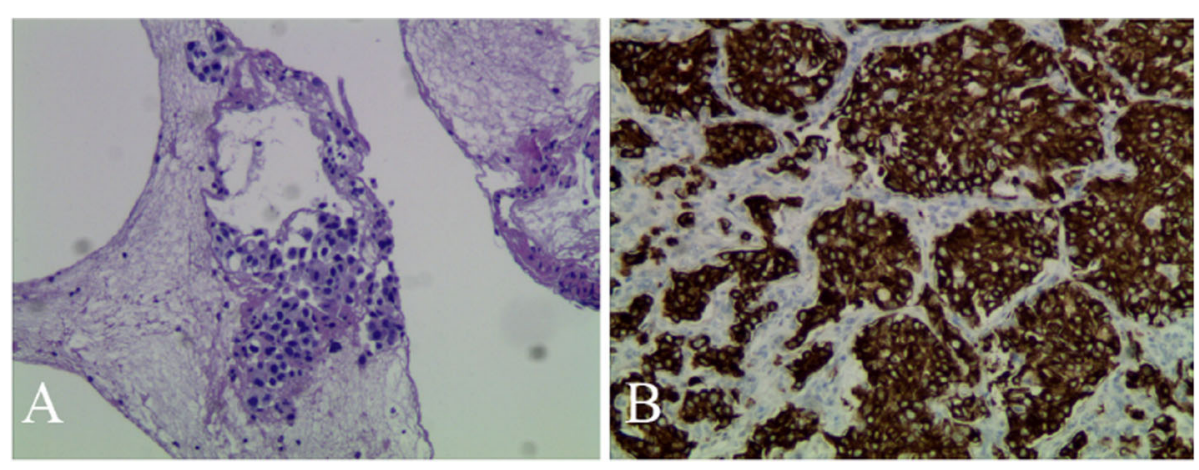

Fig. 4 Pathological examination of bronchial tissue in the lower lobe of the right lung shows adenocarcinoma 
intrathoracic suppurative. Earlier diagnosis and proper drainage surgery with effective antibiotics treatment are very important, antimicrobial treatment should be more than 5 weeks. When complex pulmonary infection interferes with the CT diagnosis, clinical suspicion of lung cancer should be increased if G.adiacens or Eikenella corrodens is detected from a pulmonary infection.

\section{Abbreviations}

G.adiacens: Granulicatella adiacens; CT: Computed tomography; WBCC: White blood cell count; PLT: Platelet; IL-6: Interleukin-6; PCT: Procalcitonin; CPR: Creactive protein; ALB: Albumin

\section{Acknowledgements}

Thanks to the Dr. Xiaofeng Sun for professional explaination of the bacteria.

\section{Authors' contributions}

Medical guide: SXF HX, XLL. Conceptualization and Data collection: YS, WLL, YL, XL. Writing - original draft: YS. Writing - review \& editing: SXF, WLL, HX, $\mathrm{XLL}, \mathrm{YL}, \mathrm{XL}$. All authors have read and approved the manuscript.

\section{Funding}

Not applicable.

\section{Availability of data and materials}

All the data and materials in this report are from the authors on reasonable request.

\section{Declarations}

\section{Ethics approval and consent to participate}

Not applicable.

\section{Consent for publication}

Written informed consent was obtained from the patient for publication of this report and any accompanying images.

\section{Competing interests}

All the authors declare there are no conflicts.

\section{Author details}

${ }^{1}$ The first Clinical College of Xinjiang Medical University, Urumqi city, China. ${ }^{2}$ Gansu University of traditional Chinese Medicine, Lanzhou, Gansu, China. ${ }^{3}$ Infection center, the First Affiliated Hospital of Xinjiang Medical University, Urumqi city, China.

\section{Received: 20 January 2021 Accepted: 17 May 2021}

Published online: 08 July 2021

\section{References}

1. Groff DB, Rapkin RH. Primary lung abscess in childhood. J Med Soc N J. 1974;71(9):649-52.

2. Hirshberg B, Sklair-Levi M, Nir-Paz R, Ben-Sira L, Krivoruk V, Kramer MR. Factors predicting mortality of patients with lung abscess. Chest. 1999; 115(3):746-50. https://doi.org/10.1378/chest.115.3.746.

3. Kuhajda I, Duric D, Koledin M, Ilic M, Tsavlis D, Kioumis I, et al. Electric vs. harmonic scalpel in treatment of primary focal hyperhidrosis with thoracoscopic sympathectomy. Ann Transl Med. 2015;3(15):211.

4. Brouqui P, Raoult D. Endocarditis due to rare and fastidious bacteria. Clin Microbiol Rev. 2001;14(1):177-207. https://doi.org/10.1128/CMR.14.1.177-2 07.2001 .

5. Giuliano S, Caccese R, Carfagna P, Vena A, Falcone M, Venditti M. Endocarditis caused by nutritionally variant streptococci: a case report and literature review. Infez Med. 2012;20(2):67-74.

6. Padmaja K, Lakshmi V, Subramanian S, Neeraja M, Krishna SR, Satish OS. Infective endocarditis due to Granulicatella adiacens: a case report and review. J Infect Dev Countries. 2014;8(4):548-50. https://doi.org/10.3855/ jidc.3689.
7. Rosenthal O, Woywodt A, Kirschner P, Haller H. Vertebral osteomyelitis and endocarditis of a pacemaker lead due to Granulicatella (Abiotrophia) adiacens. Infection. 2002;30(5):317-9. https://doi.org/10.1007/s15010-002-2104-3.

8. Cargill JS, Scott KS, Gascoyne-Binzi D, Sandoe JAT. Granulicatella infection: diagnosis and management. J Med Microbiol. 2012;61(Pt 6):755-61. https:// doi.org/10.1099/jmm.0.039693-0.

9. Woo PC, Fung AM, Lau SK, Chan BY, Chiu SK, Teng JL, et al. Granulicatella adiacens and Abiotrophia defectiva bacteraemia characterized by $165 \mathrm{rRNA}$ gene sequencing. J Med Microbiol. 2003;52(Pt 2):137-40. https://doi.org/10.1 099/jmm.0.04950-0.

10. Hsiao WW, Li KL, Liu Z, Jones C, Fraser-Liggett CM, Fouad AF. Microbial transformation from normal oral microbiota to acute endodontic infections. BMC Genomics. 2012;13(1):345. https://doi.org/10.1186/1471-2164-13-345.

11. Patil SM, Arora N, Nilsson P, Yasar SJ, Dandachi D, Salzer WL. Native valve infective endocarditis with osteomyelitis and brain abscess caused by Granulicatella adiacens with literature review. Case Rep Infect Dis. 2019; 2019:4962392.

12. Perna A, Ricciardi L, Sturiale CL, Fantoni M, Tamburrelli FC, Bonfiglio N, et al. Skipped vertebral spontaneous spondylodiscitis caused by Granulicatella adiacens: case report and a systematic literature review. J Clin Orthop Trauma. 2020;11(5):937-41. https://doi.org/10.1016/j.jcot.2019.07.002.

13. Pilli $\mathrm{S}$, Murjaneh $\mathrm{S}$. Granulicatella adiacens endophthalmitis after phacoemulsification cataract surgery. J Cataract Refract Surg. 2020;46(12): e30-4. https://doi.org/10.1097/j.jcrs.0000000000000355.

14. Quenard F, Seng P, Lagier JC, Fenollar F, Stein A. Prosthetic joint infection caused by Granulicatella adiacens: a case series and review of literature. BMC Musculoskelet Disord. 2017;18(1):276. https://doi.org/10.1186/s12891-01 7-1630-1.

15. Teo L, Looi A, Seah LL. An unusual causative agent for an orbital abscess: Granulicatella Adiacens. Orbit. 2011;30(3):162-4. https://doi.org/10.3109/01 676830.2011 .569631

16. Stock CT, Ho VP, Towe C, Pieracci FM, Barie PS. Lung abscess. Surg Infect. 2013;14(3):335-6. https://doi.org/10.1089/sur.2012.060.

17. Yazbeck MF, Dahdel M, Kalra A, Browne AS, Pratter MR. Lung abscess: update on microbiology and management. Am J Ther. 2014;21(3):217-21. https://doi.org/10.1097/MJT.0b013e3182383c9b.

18. Hammond JM, Potgieter PD, Hanslo D, Scott H, Roditi D. The etiology and antimicrobial susceptibility patterns of microorganisms in acute communityacquired lung abscess. Chest. 1995;108(4):937-41. https://doi.org/10.1378/ chest.108.4.937.

19. Christensen JJ, Facklam RR. Granulicatella and Abiotrophia species from human clinical specimens. J Clin Microbiol. 2001;39(10):3520-3. https://doi. org/10.1128/JCM.39.10.3520-3523.2001.

20. Seng P, Drancourt M, Gouriet F, La Scola B, Fournier PE, Rolain JM, et al. Ongoing revolution in bacteriology: routine identification of bacteria by matrix-assisted laser desorption ionization time-of-flight mass spectrometry. Clin Infect Dis. 2009:49(4):543-51. https://doi.org/10.1086/600885.

21. Ratcliffe P, Fang H, Thidholm E, Boräng S, Westling K, Özenci V. Comparison of MALDI-TOF MS and VITEK 2 system for laboratory diagnosis of Granulicatella and Abiotrophia species causing invasive infections. Diagn Microbiol Infect Dis. 2013;77(3):216-9. https://doi.org/10.1016/j.dia gmicrobio.2013.07.008

22. Téllez A, Ambrosioni J, Llopis J, Pericàs JM, Falces C, Almela M, et al. Epidemiology, clinical features, and outcome of infective endocarditis due to Abiotrophia species and Granulicatella species: report of 76 cases, 20002015. Clin Infect Dis. 2018;66(1):104-11. https://doi.org/10.1093/cid/cix752.

23. Zhang H, Liu Q, Lei Y, Zhou J, Jiang W, Cui Y, et al. Direct interaction between CD155 and CD96 promotes immunosuppression in lung adenocarcinoma. Cell Mol Immunol. 2020. https://doi.org/10.1038/s41423-02 0-00538-y.

24. Pohlson EC, McNamara JJ, Char C, Kurata L. Lung abscess: a changing pattern of the disease. Am J Surg. 1985;150(1):97-101. https://doi.org/10.101 6/0002-9610(85)90016-9.

25. Hu L, Lin J, Li J, Cao Y, Lin L. Lung abscess secondary to lung cancer with Eikenella corrodens and Streptococcus anginosus: a case report. BMC Infect Dis. 2020;20(1):351. https://doi.org/10.1186/s12879-020-05054-y.

26. Knudsen TD, Simko EJ. Eikenella corrodens: an unexpected pathogen causing a persistent peritonsillar abscess. Ear, Nose, Throat J. 1995;74(2):1147. https://doi.org/10.1177/014556139507400212.

27. Baddour LM, Wilson WR, Bayer AS, Fowler VG Jr, Tleyjeh IM, Rybak MJ, et al. Infective endocarditis in adults: diagnosis, antimicrobial therapy, and 
Management of Complications: a scientific statement for healthcare professionals from the American Heart Association. Circulation. 2015;132(15): 1435-86. https://doi.org/10.1161/CIR.0000000000000296.

28. Gould FK, Denning DW, Elliott TS, Foweraker J, Perry JD, Prendergast BD,

et al. Guidelines for the diagnosis and antibiotic treatment of endocarditis in adults: a report of the working party of the British Society for antimicrobial chemotherapy. J Antimicrob Chemother. 2012;67(2):269-89. https://doi.org/10.1093/jac/dkr450.

29. Tuohy MJ, Procop GW, Washington JA. Antimicrobial susceptibility of Abiotrophia adiacens and Abiotrophia defectiva. Diagn Microbiol Infect Dis. 2000;38(3):189-91. https://doi.org/10.1016/S0732-8893(00)00194-2.

30. Kanamoto T, Terakubo S, Nakashima H. Antimicrobial Susceptibilities of oral isolates of abiotrophia and granulicatella according to the consensus guidelines for fastidious bacteria. Medicines (Basel, Switzerland). 2018;5(4): 129.

\section{Publisher's Note}

Springer Nature remains neutral with regard to jurisdictional claims in published maps and institutional affiliations.

Ready to submit your research? Choose BMC and benefit from:

- fast, convenient online submission

- thorough peer review by experienced researchers in your field

- rapid publication on acceptance

- support for research data, including large and complex data types

- gold Open Access which fosters wider collaboration and increased citations

- maximum visibility for your research: over $100 \mathrm{M}$ website views per year

At $\mathrm{BMC}$, research is always in progress.

Learn more biomedcentral.com/submissions 